\title{
EXPLORING THE ISSUE OF ENVIRONMENTAL DEGRADATION IN THE ERA OF MASS CONSUMERISM \\ AND DIGITAL MEDIA AS THE SOLUTION
}

by

\author{
Elspeth A. Poulson \\ BAH, Queen's University, 2017 \\ A Major Research Project \\ presented to Ryerson University
}

in partial fulfillment of the requirements for the degree of

MASTER of DIGITAL MEDIA

In the program of Digital Media

Toronto, Ontario, Canada, 2018

(C) Elspeth A. Poulson, 2018 


\section{AUTHOR'S DECLARATION}

I hereby declare that I am the sole author of this MRP. This is a true copy of the MRP, including any required final revisions.

I authorize Ryerson University to lend this MRP to other institutions or individuals for the purpose of scholarly research.

I further authorize Ryerson University to reproduce this MRP by photocopying or by other means, in total or in part, at the request of other institutions or individuals for the purpose of scholarly research.

I understand that my MRP may be made electronically available to the public. 
Exploring the Issue of Environmental Degradation in the era of Mass Consumerism and Digital Media as the Solution

Elspeth A. Poulson

Master of Digital Media, Ryerson University

2018

\begin{abstract}
As the price of clothing continues to globally decline, demand and consumption rise in tandem. This relationship between mass production and consumption has earned the title "fast fashion" as it values efficiency and inexpensive manufacturing methods and materials. The environmental costs however, of producing, consuming and ultimately discarding so much clothing is unparalleled. Although there is growing pressure on the industry to engage in more socially and environmentally-responsible practices, this pressure does not in any fundamental way contradict the logic of consumer capitalism. The following research project places the responsibility and agency of conscious consumer behaviour back into the hands of individuals in hopes of disrupting the cycle of mass production and consumption. Leveraging the power and influence of social media, this project reflects upon the current role of Instagram as a propagator of consumer culture and reimagines it as a catalyst for mindful purchasing behaviour among the female millennial demographic.
\end{abstract}




\section{Acknowledgments}

This MRP has been, in many ways, one of the most difficult and rewarding projects I've ever taken on. There were moments when I was absolutely certain I would never finish it and moments where I lost faith in my own abilities. To my supervisor, Margaret, thank you for your constant encouragement and belief in me when I had none left in myself. Thank you and for your insight, advice and dedication to my success. You see the world through an artist's eyes and it was a privilege to learn from and work alongside you. To my second reader, Alya, I could never express how grateful I am for everything you've done. You are an exceptional teacher, listener and friend. I was lucky to work with you and learn from you. And to my parents, everything I've done and all that I've accomplished I owe to you. You show me each day what it means to work hard, be grateful and always look for the best in everything. Your ability to handle all of life's curveballs with grace and humor is a true testament to your strength. I hope I've made you proud. 


\section{Table of Contents}

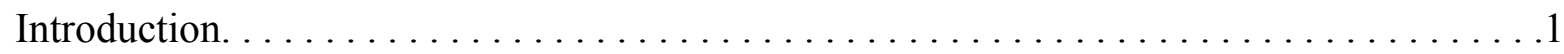

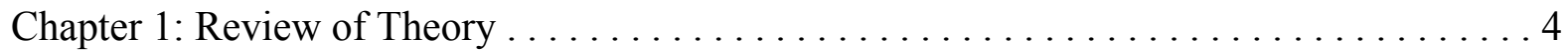

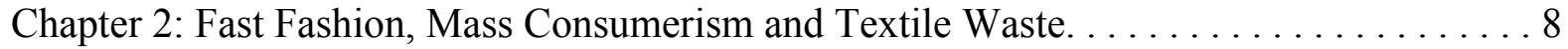

Chapter 3: Landscape Research of Other Platforms that work within the

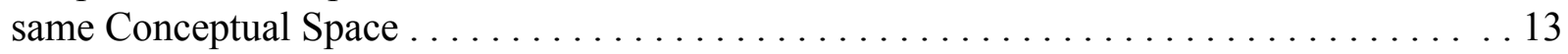

Chapter 4: Persuasion Techniques \& the Benefits of Positive Thinking. . . . . . . . . 18

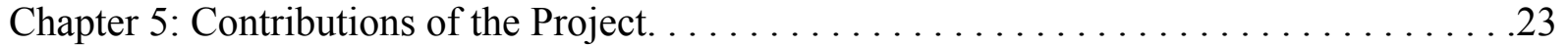

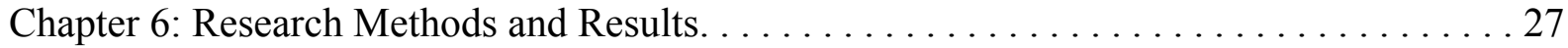

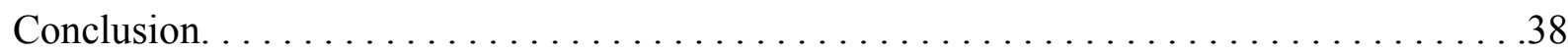

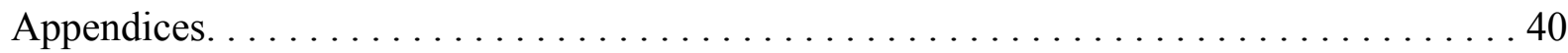

References. ......................................47 


\section{List of Figures}

2.0 Results from a 2017 study based on 2,000 Instagram users. . . . . . . . . . . . . . 10

4.0 Environmental activist, Nicolas Hulot's 2005 ad campaign. . . . . . . . . . . . . . . . . . 20

4.1 Environmental activist, Nicolas Hulot's 2005 ad campaign. . . . . . . . . . . . . . . . 20

5.0 Email correspondence with director of Mmore cases, on online brand specializing in

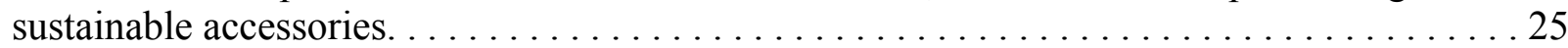

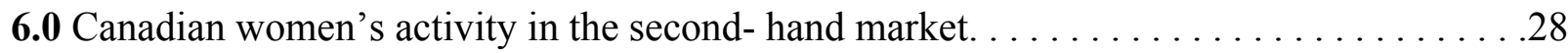

6.1 Canadian men's activity in the second- hand market. . . . . . . . . . . . . ..28

6.2 Value Village's Instagram page used for comparison purposes in conjunction with other thrift

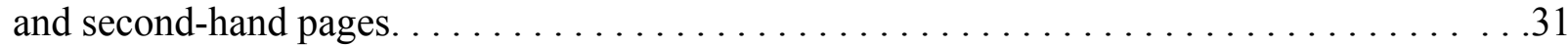

6.3 Salvation Army's Instagram page used for comparison purposes in conjunction with other

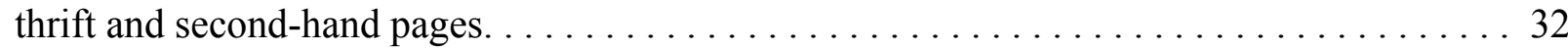

6.4 Atomic Thrift's Instagram page used for comparison purposes in conjunction with other thrift

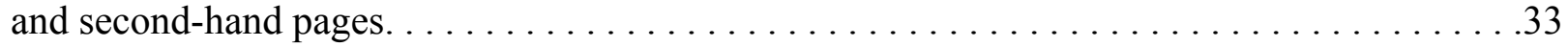
6.5 The Ever After Club's Instagram page used for comparison purposes in conjunction with

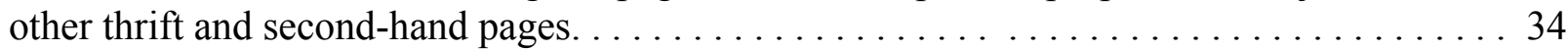
6.6 Responses to question, "Do you follow any thrift/second-hand clothing pages on Instagram?"

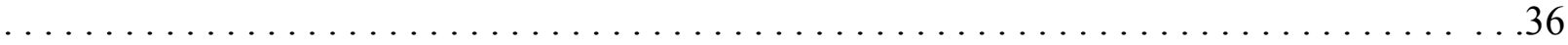

6.7 Responses to question, “Do you follow clothing brands/companies on Instagram?” . . . . .36

\section{List of Appendices}

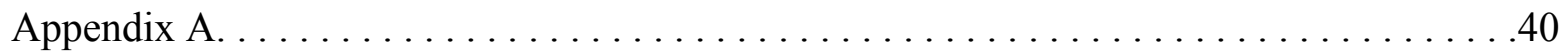

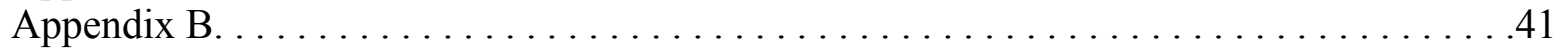

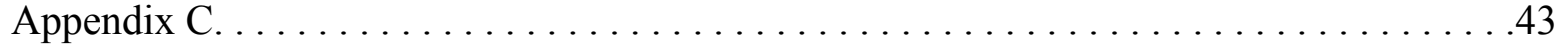

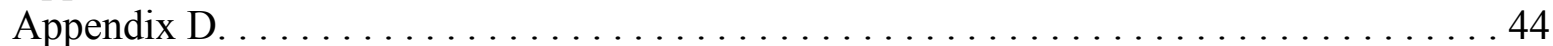


"Never doubt that a small group of thoughtful, committed citizens can change the world; indeed, it's the only thing that ever has."

-Margaret Mead 


\section{Introduction}

As manufacturing companies around the world continually exploit non-renewable resources and cheap labour, the price of clothing diminishes in tandem on a global scale. Luz Claudio (2007) discusses in her, article, Waste Couture, the ways in which globalization and consumerism contribute to the era of "fast fashion" which capitalizes on high productivity and low-quality goods, thus allowing for inexpensive retail prices. In a world driven by efficiency and profit, large companies often sacrifice the welfare of industry workers and the environment in order to cut costs and increase revenue. Simultaneously, the fashion industry works to convince consumers that they must continually rid themselves of last season's clothing and buy new items to keep up with ever-changing trends.

The rise of digital media and e-commerce have concurrently assisted to usher in the era of fast fashion as purchasing is simpler and more efficient than ever before. Today, nearly everything, from clothing to technology to groceries can be ordered online or through a mobile device. Lana Borgie (2014) explains in her article, Trends in producer prices between ecommerce and brick-and-mortar retail trade establishments,

"By the first quarter of 2014, e-commerce grew to about 6 percent of total retail sales in the United States. Between 2009 and 2014,e-commerce sales increased at an average annual rate of 16 percent, compared with a 5-percent growth rate in total retail sales" (Borgie 2014).

The growth of e-commerce and globalization have not only made purchasing simpler and more efficient, they also grant consumers access to a broader range of products that are no longer restricted to their specific city or even country. Consumers now have infinite choices and as a result, retail companies must compete to differentiate themselves and their products through 
branding techniques. Consumers are no longer sold a physical product but rather the lifestyle that the product represents. Redbull, for example, the popular energy drink company leverages the power of digital and social media to promote a lifestyle that appeals to its target demographic. As Firas Kittaneh (2015) discusses in his article, Use Content Marketing to Sell a Lifestyle, not a product,

"The company proudly displays its logo everywhere, of course, but the content it produces and promotes often does not mention the quality of its product at all. Instead, Red Bull shines the spotlight on surfers, wing gliders and ice climbers to highlight incredible people doing amazing things. Red Bull has built an empire by creating culture instead of selling its products outright" (Kittaneh 2015).

Consumers are driven and motivated by what they see on their screens. Brands sell idealistic experiences and lifestyles through digital and social media and the influence on consumers is immense. People buy more and more to try and live out the lifestyles that they have been led to believe are reality. Consumption has become a mindless distraction, an addiction as opposed to a necessity. The Netflix Documentary (2015) Minimalism discusses,

“....and we're encouraged to maintain this addiction through technology and information. There's definitely this illusion of what our lives should look like, whether its advertising, or your Instagram or Facebook feed...There can be an immense amount of dissatisfaction in trying to live that way and many of us see no alternative but to live that way (Minimalism 2015)."

Millennials are driven by the desire for experience and like most consumers, make purchases, not because they need that certain product but because they want to feel the fulfillment and contentment that they think that product will bring. However, it is difficult for them to understand that the meaning and fulfillment they seek cannot be purchased when the world around them is constantly convincing them that they will only feel fulfilled and find meaning in their lives if they continue to consume more. This project seeks to offer people, 
specifically millennial women an alternative, by creating a new public located outside of the logic of mass consumption.

Using the commonplace digital platform, Instagram, this project assesses its current role as a facilitator of mindless consumption and reimagines it as a catalyst for conscious consumer behaviour, specifically with regards to clothing. It disrupts the social media sphere by creating a space that does not promote idealistic and unachievable lifestyles rooted in consumerism. It instead promotes a lifestyle located outside of the logic of mass consumption. As this project was developed in Toronto and makes reference to stores and neighbourhoods in the Toronto area, the preliminary target audience is millennial women (ages 18-35) living in Toronto with access to technology. The Instagram page created for the purpose of this project encourages millennial women to play a larger role in the second-hand clothing industry and reduce the amount of new clothing that they purchase, reminding them to think critically about their underlying motives for consumption.

In the process of creating a public located in mindful purchasing behaviour and emphasizing that fulfillment is not a tangible item that can be bought, the project encourages millennial women to get involved in more environmentally sustainable practices which in and of itself is a far more fulfilling pursuit. 


\section{Chapter 1.0: Review of Theory}

It is important to recognise within the field of textile waste in the fashion industry, there are multiple studies and ample research that precede this project. The following works and studies helped to shape the approach and research methods of this project beginning with Luz Claudio's (2007) article, Waste Couture: Environmental Impact of the Clothing Industry. In a world driven by efficiency, it is common to observe large companies sacrificing the welfare of industry workers and the environment in order to cut costs and increase profit. Luz Claudio discusses in her article the relationship between cheap labour and cheap manufacturing and the effect on clothing prices. Claudio discusses in her conclusion a handful of companies that have made efforts or are working towards eco-friendlier options for their clothing manufacturing such as Patagonia who uses recycled plastic and soda bottles to create many items from their clothing line. It is interesting to note however, that Michael Braungart and William Mcdonough's (2010) book Cradle to Cradle rejects this technique explaining that those soda bottles were not created with the intention of becoming anything else after their life as a soda bottle and, "wrestling them into this form has required as much energy - and generated as much waste as producing a new-"

in this case, Patagonia sweater (Braungart, Mcdonough 2010).

Additionally, this project studies Kate Fletcher's (2012) work, Fashion and Sustainability which outlines the variety of fibres that make up the textile industry, highlighting the benefits and consequences of each. She calls upon designers and clothing companies to reconsider their 
role in preserving the planet's resources and make the conscious decision to create clothing that is durable and built to last.

Moreover, this paper and project relies on the work of Mary Pipher (2012), clinical phycologist, environmental activist and author of the book, Green Boat. Pipher explains the reasons why people have a tendency to shut down emotionally when they feel overwhelmed by issues that are not easily resolvable. Her insight helped to lead this project in a direction that would encourage millennial women to get involved and reframe environmental sustainability as an achievable and exciting objective as opposed to a threat or punishment for bad behaviour. Finally, this project leverages the 2015 documentary, Minimalism which offers insight into the world of mass consumerism and explains the ways in which advertising and marketing agencies convince people that they can buy their way to contentment and fulfillment. The result is constant dissatisfaction among consumers and in turn, more consumption.

\subsection{Situation Within the Field of Research}

Of the works discussed in the previous section, there is consistently a major gap in the research and solutions put forth. Of the papers and projects that even offered a possible solution, all were hypothetical and large-scale, ones that would take years to create or implement into society. Other studies, discussed the need for improvements to major corporations and businesses such as Luz Claudio's article which called for clothing manufacturers to use sustainably grown cotton and other fiber crops in their clothing. Claudio briefly acknowledges, however, that sustainably grown, organic crops would reduce efficiency and increase expenditures. Therefore, encouraging profit-driven companies to adhere to such guidelines is in most cases unrealistic.

Nike, for example, one of the most profitable sportswear companies in the world announced back 
in 2010 that going forward, their company would blend 5\% organic cotton into all of their cotton products (Fletcher 2007). Although not entirely insignificant, major textile manufacturers and clothing companies such as Nike are not doing nearly enough to make substantial impacts on the issue of sustainability in the fashion and textile industry. Organic cotton still only represents only $1 \%$ of global cotton production (Fletcher 2007). Not one of the studies examined throughout this project suggested simply producing less and consuming less as a way to break the cycle of mass production and consumption. Marketing and advertising agencies capitalize on generating constant demand from consumers and this growing demand can only be met by manufacturers by engaging in the most efficient and unsustainable practices. Another unfortunate reality is that there is no more time to wait and to place the responsibility on others. The responsibility needs to be placed back into the hands of individuals through their everyday decisions in a way that doesn't feel like a chore or an inconvenience. People need to be reminded that they have agency over their decisions and take back control from the media which dictates consumerism as the key to happiness. People are often not willing to make sacrifices in their day to day lives because there are already so many other ongoing obligations and responsibilities. An added responsibility or added cost of being more environmentally responsible feels like a nuisance. Millennialfocused publisher, Bustle, conducted a 2017 study to learn more about the wants and needs of female consumers in the 18-34-year-old age group. Of the 1,000 women who participated in the study, only $34 \%$ agreed that they would be willing to pay more for an environmentally-friendly product (Thorpe 2017).

Therefore, this project aims to disrupt the current role of social media and encourage more mindful consumption by offering a realistic solution instead of simply demanding that people consume less or spend more money. It is important to remind people that buying many 
inexpensive items eventually adds up over time and it would be much more worthwhile and more in line with sustainable practice to buy fewer, higher quality items or higher quality items from the second-hand market. Therefore, people don't have to actually spend more than they already are buying lots of inexpensive goods. In addition, they don't have to quickly dispose of nearly as many of these inexpensive goods that are not built to last.

The consistent gap across the works referenced in this study is the lack of legitimate solutions that encourage individuals to get involved and participate in sustainable practices. Using digital media, specifically social media, this major research project closes the gap in existing research and encourages individuals to practice more sustainable, conscious clothing consumption in a manner that feels enjoyable, exciting and fulfilling. Individuals can make an impact even if it is on a small scale and the effects could eventually radiate outwards in a ripple effect, restructuring the current production and consumption model. The change has to begin with the individual consumers and with ways in which we consider our role as producers of meaning. Manufacturers and clothing companies will always follow suit based on changes in consumer demands. Digital media is the present and it is the future and this project is an example of its power as a tool for positive change. Therefore, this project is situated within the field of fashion and sustainability as an influencer of conscious consumer behaviour using Instagram to create a mindful public, an entirely difference purpose than it was intended. Furthermore, this project frames matters of environmental sustainability as attainable and exciting and inclusive. Perhaps most importantly, this project serves as a reminder that mindless consumption will never lead to fulfillment. If one understands that using mindless consumption as a means to bring fulfillment to their lives will only lead to ultimate dissatisfaction, they'll be encouraged to seek fulfillment elsewhere and be far more likely to find it. 


\section{Chapter 2.0: The Major Contributors of Fast Fashion, the Environmental Repercussions and Social Media as the Solution}

Each year, the impact of human behaviour on the environment becomes more apparent and the statistics on pollution and waste more alarming. A CBC news report on textile waste reported that in North America alone, 70 million tons of clothing end up in landfill annually (CBC News 2018). An article from volume 8 of the Nature Climate Change Journal states:

"clothing costs have risen slower than those of other consumer goods, increasing their affordability, and there will be continued growth as the middle class expands and purchases increase to match this demographic shift. This combination of factors is expected to result in a tripling of resource consumption by 2050 [compared to 2000]" (Nature Climate Change 2018).

In addition to the issue of mass consumption and disposal, the process of creating new clothing uses a considerable energy and non-renewable resources. Polyester, the most commonly manufactured fabric in the fashion industry is made from petroleum, a non-renewable resource must be extracted from the ground and refined. Colin Beavan, author of No Impact Man explains, "this mindless consumption, this same thing that's not making us happy, is also causing the degradation of our habitat. We can afford to have 350 parts per million of carbon dioxide in the atmosphere. We're closing in on 400 parts per million. It's caused by the burning of oil, of natural gas of coal, of all the things that we use to power our consumer economy, to power the making of [stuff] we don't need" (Minimalism 2015).

A simple solution to this environmental crisis linked to consumption is to offer people viable alternatives that will over time change consumer culture. Instead of telling people that they need to stop consuming which is an unrealistic goal, the idea of consumption and the idea of goods themselves needs to change. Second-hand clothing needs become more normalized and 
more widely accepted. As this project focuses particularly on the issue of consumption with regards to fast fashion, it is imperative to look at the key contributors of the problem, and then implement a solution that aligns with the interests of that same demographic, in this case Instagram, and utilise it in a more constructive manner. Simply put, female millennials with access to technology are the largest contributors to the problem of fast fashion according to a 2016 study from Bard College titled, An Analysis of the Fast Fashion Industry. Therefore, persuading them to change their behaviour must come through a platform that they understand and with which they engage frequently.

\subsection{Social Media as the Solution}

This section demonstrates the influence and reach of social media and that when principles of design and persuasion techniques are properly applied through the Instagram platform, it is possible to influence the decision-making of a major demographic to which Instagram appeals. 


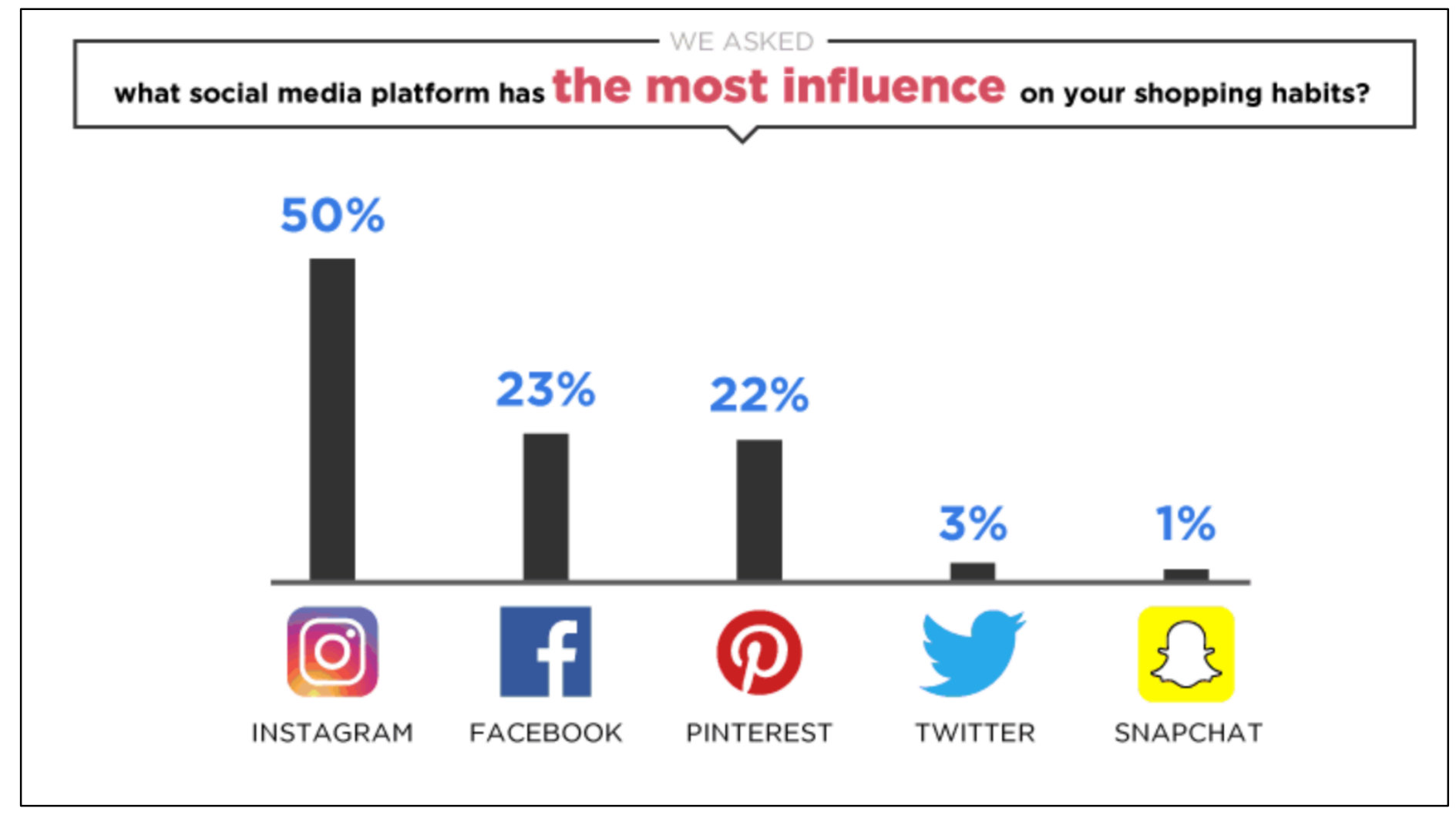

Figure 2.0 Results from a 2017 study based on 2,000 Instagram users, 60\% of whom were millennials and 77\% of whom were female (Rebecca 2017).

The new clothing industry currently has a major competitive advantage over the secondhand clothing industry in terms of marketing to millennials, particularly women. These clothing companies use social media to build and promote their brands because they understand that that is how they can best connect and attract their target audience. Yet, the thrift and second-hand clothing market seems to lack this social media presence almost entirely. Of the thrift stores and second-hand stores/blogs that are active on Instagram, most are lacking the basic marketing 
techniques that attract the millennial women audience. Millennial women are seldom the intended audience for thrift and second-hand clothing as the second-hand clothing market has gained the reputation as an affordable option for those of low socio-economic status. Using Instagram, this project aims to attract the female millennial demographic to the second-hand clothing industry and direct them away from fast fashion. The 2016 study from Bard College titled, An Analysis of the Fast Fashion Industry explains that technology and digital media play a major role in connecting young people to the fashion and celebrity culture which fuels consumerism. The author, Annie Linden, highlights in her research not only who the fast fashion industry attracts but why. One particularly noteworthy motive for these young women is the idea that fast fashion is exactly that: fast. Linden references a study conducted by Karen Miller, a professor in consumer economics and marketing. Miller notes in her study a reoccurring theme that consumers of fast fashion like the idea that each style produced by a fast fashion company such as H\&M or Zara is only available for a limited amount of time before the next trend is introduced:

"These consumers like that there is a brief window to get a product because to them that means by the time they wear the product, someone who sees it and likes it will no longer be able to find it at the fast fashion retailer" (Miller 2013).

This study was crucial to the development of this project as it highlighted the fact that fast fashion consumers, although influenced by celebrity culture and fashion blogs, still want to maintain a unique style and differentiate themselves through original clothing pieces. Therefore, second-hand shopping can and should be incredibly appealing to the consumers of fast fashion because items purchased second-hand are far more unique and it is unlikely to ever see another 
person with exactly the same piece of clothing. The Instagram page for this project, titled, The Ever After Club, made a point of leveraging this information when creating content for the page. Many of the captions on The Ever After Club's post make reference to the fact that the clothing displayed is unique and unlikely to be found anywhere else, appealing to the idea of scarcity and therefore demand. 


\section{Chapter 3.0: Landscape Research of Other Platforms that work within the same Conceptual Space.}

This major research project stemmed from a vision of reinventing the ways in which people, millennial women in particular think about their clothing consumption habits and their inextricable link to textile waste. Originally, it was anticipated that this issue could best be explored through the creation and development of an app. The app would function as a buying and selling platform for Toronto residents that was strictly for clothing, thus differentiating it from other platforms such as Craigslist and Kijiji. However, many similar apps already existed

that were all battling for an audience and users such Tradesy, Threadflip, ThredUp, DePop and Bunz to name just a few. These apps all function as buying and selling platforms for used clothing in various cities and countries. Creating another app that would likely end up lost in the vast array of pre-existing apps would not contribute legitimate and real-world change to an important issue. Furthermore, in order to function, the app would have required a level of coding that was not accessible or attainable given the time constraint. Although the app could have been left as a prototype, the idea of this project is to encourage real change from real individuals. It was never intended to be hypothetical. There is no more time for "what if" scenarios with regard to the environment. In keeping with sustainable practice and recognizing the urgency of the situation, the most constructive way to move forward was to use and leverage resources that were already available. The purpose of the project, after all, is to encourage people to use, reuse and repurpose resources that are already available. This project is meant to encourage small-scale solutions that do not appear so daunting and unachievable and to reframe sustainability as a goal that can actually be achieved by individuals. Even minor shifts in consumer behaviour can make 
an enormous difference and encourage change from manufacturers and marketers as well. As an article from the nature climate change journal discusses,

"... only by working together and changing behaviours will we see results. However, the individual actions of consumers can send a strong message and spark change" (Nature Climate Change 2018).

One does not need to invent a new app or a new piece of technology to make a difference. It can be as simple as redefining the way in which an existing tool was intended. Environmental sustainability does not have to be a chore. It can be integrated seamlessly into many every day choices and become an enjoyable aspect of consumer behaviour. Instead of feeling frightened or overwhelmed, people should feel motivated and capable of change. Social media is a platform and a language that this project's target demographic understands and enjoys using. It allows for the organization of photos, videos and ideas. The question became, 'how can its power and influence be harnessed to encourage certain consumer behaviour and shift people's priorities?' In order to explore this question further, it is important to fully understand the role of social media, particularly Instagram and its role in young people's lives.

\subsection{The Instagram Industry}

As of this Spring, Instagram officially hit 1 billion monthly active users (Statista 2018). It has become a powerhouse in the marketing industry used by all sorts of businesses, to easily and effectively reach their target audience. Retail companies have a major competitive edge over second-hand and thrift stores due to their social media presence alone. Young people are highly motivated and influenced by the brands that show up again and again on their Instagram feeds with enchanting and perfectly composed images. Retail companies use social media and marketing experts who know how to target their audience and keep up with the latest 
trends in social media. Yet, stores such as Value Village, Salvation Army Thrift and other smaller thrift stores and blogs pale in comparison and do not capture the attention of millennials effectively on Instagram. There is a major gap between the second-hand clothing industry and the new clothing industry that has been created by not properly leveraging the power of social media to reach a wider audience and engage young women in more sustainable options. The lack of engagement between thrift and second-hand clothing pages on Instagram and the target demographic is demonstrated through the survey results presented in chapter 6 .

\subsection{Project Development}

This project transformed into an Instagram page called The Ever After Club which launched in early June. The process began with establishing a target demographic for the page and then using techniques from other successful fashion and clothing pages to influence the layout and design of The Ever After Club page. The page features clothing exclusively purchased from consignment stores and thrift shops around Toronto. The clothing is photographed and displayed with a certain aesthetic that appeals to female millennial Instagram users. Each post is detailed with information about where the piece of clothing was purchased in Toronto, how much it cost and ways to get involved in sustainable clothing consumption in Toronto. The page aims to demystify and destigmatize the second-hand clothing industry and make it a more accessible and comprehensible community using the familiar and popular platform, Instagram. As Instagram grow and develops, it allows for individual pages to become more personalized and distinguished from one another. The Ever After Club leverages these personalization tools to create a navigational guide of Toronto thrift stores. The new "highlights" feature on Instagram for example, allows users to feature pictures and videos at the top of their 
page that are categorized into sections with titles. The Ever After Club uses highlights to to divide up the city of Toronto by neighbourhood. Each highlight features a different Toronto neighborhood and shows photos and videos of thrift and second-hand stores in that area. Each neighbourhood highlight also features photos of the clothing, location details and virtual tours through the store that offer tips and tricks on sorting through all of the available clothing which is often disorganized (See appendix A).

The page uses techniques from other successful clothing brands to create an appealing aesthetic while situating itself outside of the unrealistic ideals and lifestyles that are so omnipresent on social media. The page places emphasis on the need for people to be truly materialistic. As Juliet Schor (2015) PHD economist and Sociologist explains, people are too materialistic in the everyday sense of the word but not at all materialistic enough in the true sense of the word:

"We need to be true materialists and really care about materiality of goods. Instead, we're in a world where material goods are so important for their symbolic meaning, what they do to position us in the status system based on what adverting or marketing says they're about" (Minimalism 2015).

When used effectively, social media can reshape the way relationship between millennial women and their role as consumers. Its influence can be used to dissuade mindless consumerism instead of encourage it. It can be used to create excitement and enthusiasm about environmental sustainability. Instagram is the ideal platform to capture the attention of millennial women as it is already so integral to their everyday lives. Using the same techniques as major brand companies and fashion blogs, The Ever After Club became a page that encompassed the values of sustainability in fashion through second-hand shopping and mindful consumption while remaining relevant and appealing to the female millennial audience. The photographs on the 
page feature all thrifted and second-hand clothing which has been styled and photographed in a manner that appeals to this particular demographic. For example, vintage-style photographs that use a grainy aesthetic are particularly popular and pictures of ocean waves and tropical plants are often incorporated into fashion pages to construct more than just a fashion page but a lifestyle (Refer to Appendix B).

One of the most important characteristics to a successful fashion page on Instagram is not just to create photos and outfits that draw in millennial women, but to promote an entire lifestyle, a meaningful lifestyle. In order to grow users and keep current followers engaged, it was important to feature more than just clothing on The Ever After Club page. Pictures that capture connection to the environment, a love of the Earth and the value of enjoying little pleasures in everyday life were as important to the development of the Ever After Club brand as pictures that featured the clothing itself. There has never been a better time to develop this project as millennials are beginning to look for meaningful connections and genuine experiences. Not only do they want connect with the world around them and connect to one another, they want to share their experiences which is where so much of the appeal of social media lies. Millennials are so influenced by the media because they want to live out the lifestyles they see depicted and have those experiences for themselves. They are convinced that buying the products associated with a desirable lifestyle will bring them closer to that lifestyle.

The Ever After Club aims to show millennial women that the fulfillment and meaning they seek can and will be found outside of consumer and popular culture. The Ever After club creates a public rooted in meaningful experiences. 


\section{Chapter 4: Persuasion Techniques and the Benefits of Positive Thinking}

Techniques of persuasion are ingrained in everyday human behaviour and interactions. Psychologist, Robert Cialdini (2016), explains in his book, Influence: Science and Practice, that the way in which people frame a request or outline a sales pitch for example can drastically influence the response they receive. For example, Cialdini references an experiment conducted at Harvard university in which the researcher asked a favor to two different groups of people but slightly altered the way she framed the request. The results confirmed that people are more likely to respond positively to a request if there is a reason provided for complying to said request. This information was critical to the development of The Ever After Club because it became apparent that it was essential to highlight why purchasing second-hand and reducing the amount of new textile purchases was so important and beneficial. Although the page is meant to encourage young women to change their purchasing behaviors without it feeling so much like a chore or an obligation, it was important to add the extra layer of incentive and explain to followers why exactly their actions would be so valuable. It wasn't enough to just to promote the second-hand clothing and the stores that carried them. People want and perhaps need a reason other than the cheaper prices to buy second-hand and thrift. Luz Claudio's (2007) article, Waste Couture discusses,

"as prices and quality of new clothing continue to decline, so too will the demand for used clothing diminish. This is because in the world of fast fashion, new clothing could be bought almost as inexpensively as used clothing" (Claudio 2007).

The page offers a way for millennial women to feel good about their purchasing behavior and understand that they are contributing to a purpose far greater than themselves. Therefore, the satisfaction and contentment that comes with mindful consumption and releasing oneself from 
the vice of consumerism capitalism is the true incentive that the page offers millennial women. The Ever After Club helped to differentiate itself from other second-hand clothing pages on Instagram by establishing itself as a social enterprise that encourages a more realistic and minimalist way of life. Instead of highlighting why mass consumption was so detrimental, it reframed the issue in a positive light, explaining why mindful consumption is so valuable. The benefits of framing complex issues such as environmental sustainability in a positive manner are exemplified in chapter 4.1 through the work of Dr. Mary Pipher.

\subsection{From Idleness to Motivation}

The most important aspect of this project was to make young people feel motivated to make changes in their behaviour and create a culture of engagement with the environment and involvement in the solution. Often media that promotes environmental sustainability uses shock and fear tactics to scare people into action such as Al Gore's environmental documentary, An

Inconvenient Truth and environmental ad campaigns such as Nicholas Hulot's demonstrated below in figure 4.0 and 4.1 . 


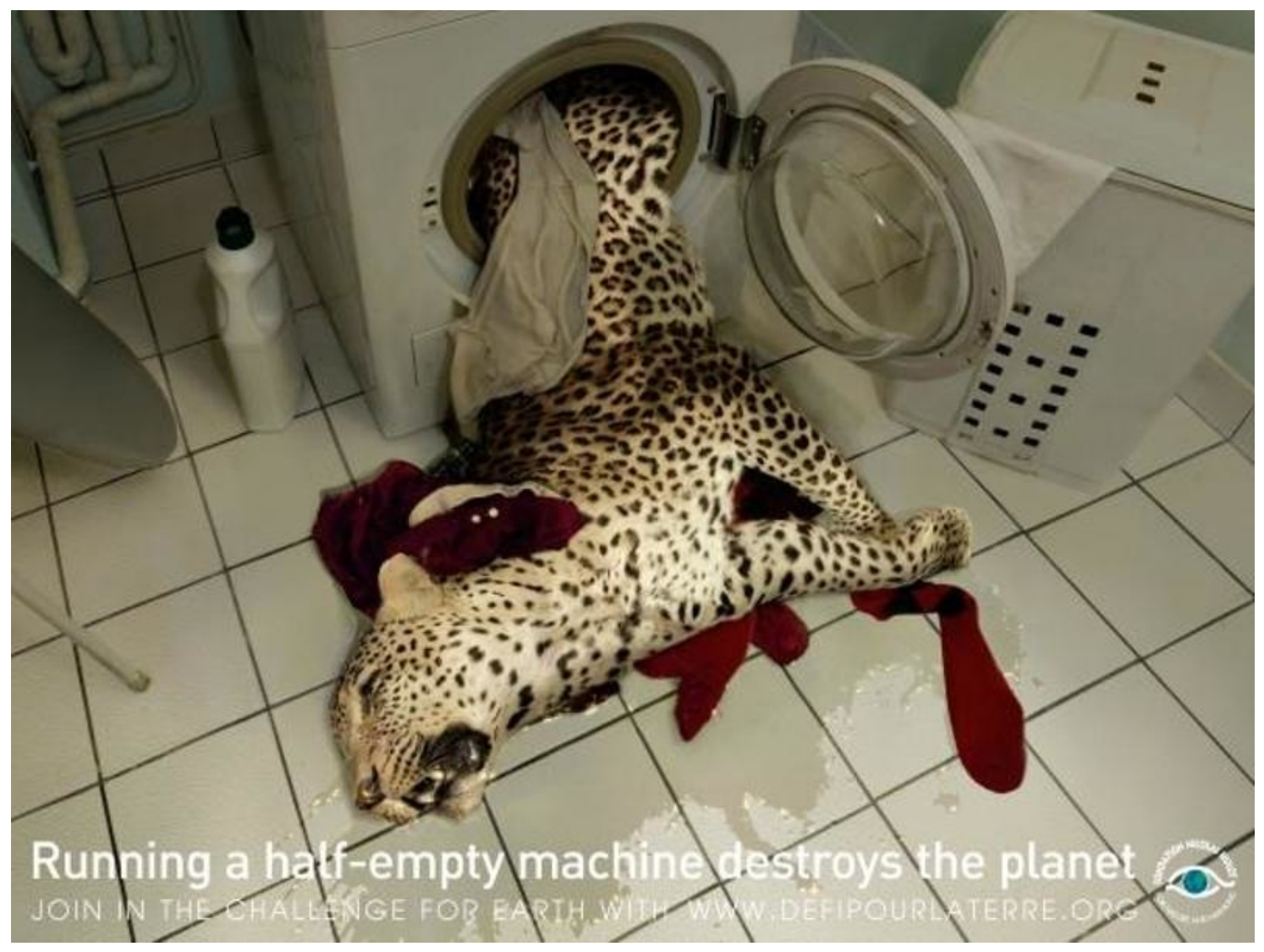

Figure 4.0 Environmental activist, Nicolas Hulot's 2005 ad campaign

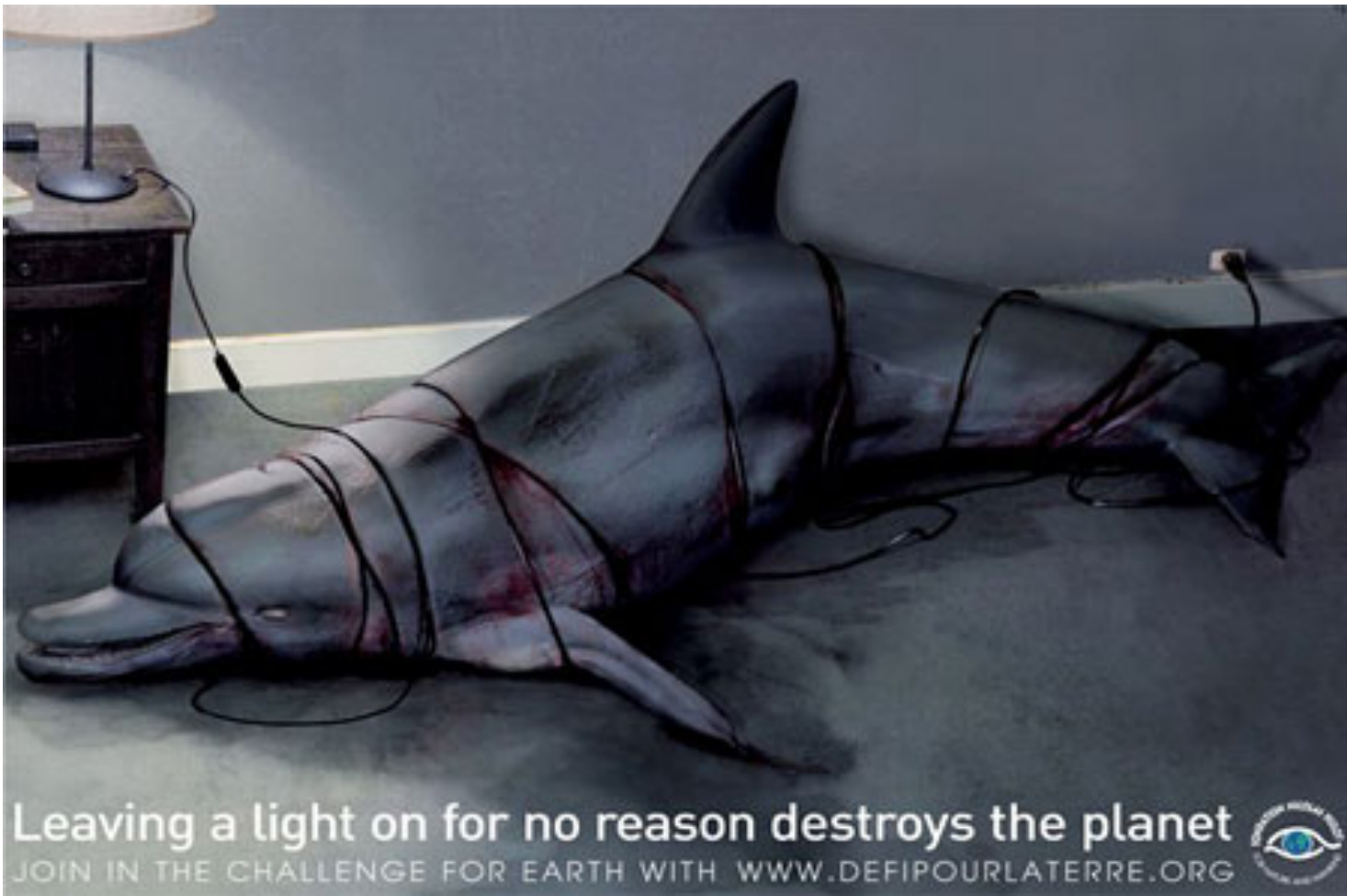

Figure 4.1 Environmental activist, Nicolas Hulot's 2005 ad campaign 
Yet, research has demonstrated people are more likely to shut down and practice avoidance rather than take action if they feel as though a problem is too overwhelming. Dr. Mary Pipher (2012), clinical phycologist environmental activist, explains this behavioural phenomenon in her book The Green Boat as well as her 2012 TED talk. She explains that people are constantly inundated with frightening information and statistics regarding environmental degradation and that human coping mechanisms, communication skills and problem solving abilities have not evolved quickly enough to properly process and absorb the masses of negative and alarming information. Crises involving the environment are so enormous in their implications that is is difficult for people to really cope with and act upon these issues when they are presented in such a hopeless manner.

"Oftentimes, because we don't know how to respond, we don't respond. We develop what phycologists call 'learned helplessness' and our sense that we are powerless becomes a selffulfilling prophecy" (Pipher 2012).

The clothing industry is a massive contributor to pollution and waste and the implications of continuing down this road are frankly terrifying. Yet, the solution doesn't have to be. Pipher goes on to quote neuroscientist, Dan Siegel stating, "the mind functions best when it acts as if there is hope (Pipher 2012)."

If practicing environmental sustainability is continued to be framed as a punishment for human being's negative actions, it will not inspire change. However, if millennials, particularly millennial women, are targeted through a platform that they understand and on which they enjoy spending time, they will be more likely to listen and more likely to feel capable of change especially when the message is framed in a positive and empowering manner. Pipher ends her discussion by reminding her listeners, 
"we can never know the significance of our individual actions, but we can act every day as if our actions are significant" (Pipher 2012).

The success and influence of The Ever After club is difficult to quantify and substantiate as one cannot know exactly how many people have been affected by the Ever After Club's message and who will actually take action as a result of interacting with the page. There is however, enough evidence to prove the influence of social media on consumer behaviour that justifies the methodologies and decisions of this project. For example, a study conducted by fashion company, Dana Rebecca Designs found that of 2,000 Instagram users who were surveyed, $72 \%$ said they have made a fashion or beauty-related purchasing decision based on a post or account they saw on Instagram (Rebecca 2017). Therefore, as the page grows and reaches more people, it is likely that its message will influence the behaviour or at least the attitudes of who interact with the page. 


\section{Chapter 5: Contributions of the Project}

This project has contributed to creating a public located outside of the logic of mass consumerism through a pre-existing and familiar app. The Ever After Club breaks down the second-hand clothing market in Toronto and helps to showcase what is available and how to navigate through individual stores. The Ever After Club demonstrates what various stores around Toronto have to offer if people are simply willing to take the time to look. Using design techniques and principles, The Ever After Club helps to destigmatize the second-hand clothing market and break down barriers that deter millennial women from playing a larger role and encourage millennial women to reconsider their roles as consumers. The hope is that by encouraging mindful consumption and offering a way for millennial women to get involved in more sustainable purchasing behaviour, the current cycle of mass production and mass consumption in the clothing industry will end.

As of recently, The Ever After Club has begun receiving messages from Instagram users who are interested in purchasing the clothing they've seen featured on the page (See Appendix C). Moving forward, The Ever After Club plans to function as a small business using the Instagram app to sell the clothing that is featured on the page. Each post will remind followers that the clothing they see on the page is available for purchase and that users simply have to direct message or email the Ever After Club. Revenue generated from re-selling second-hand clothes will go toward purchasing more thrift store clothing to photograph, promote and eventually sell. The cycle itself will become a self-sustainable way of creating change in the Toronto second-hand clothing industry and people's purchasing habits and effectively put more second-hand clothing back into circulation. 
The Ever After Club has registered as an Ontario business and is currently awaiting confirmation. The Ever After Club brand has also applied for a trademark to protect its original logo which was developed using Adobe Illustrator software. Through a Nuan's search it has been determined that the name, The Ever After Club is available for registration (See Appendix D).

\subsection{Connecting with Like-Minded People in the Digital Sphere}

Using Instagram as the foundation of this project has allowed The Ever After Club page to connect with other pages that have similar missions and objectives. The Ever After Club has recently partnered with Mmore Cases, an environmentally conscious company who uses only

natural, renewable resources and sustainable practices to create sleek and durable phone cases as opposed to the cheap, plastic cases that are not built to last. The company contacted The Ever After Club via email and offered to send one of their cases at a 70\% discount. In exchange, The Ever After Club promoted the phone case on its Instagram page and encouraged others to make similar environmentally-conscious and mindful purchases. Mmore Cases also shared The Ever After Club's post on its own page which helped the Ever After Club to gain exposure. The result was a mutually beneficial partnership between two brands with a similar mission. These kinds of connections would never have been possible without social media. 


\section{MMORE Cases}

To: theeverafterclub@gmail.com

Collaboration

\section{Hello Elspeth Poulson}

Many thanks for reaching out. It's great to hear that.

We think your work would suit perfectly to our brand and products. If you could post our world's first organic phone case on your profile and give us feedback on our product and how you experience it that would truly mean the world to us.

There is also an added benefit that this would be very interesting content for your followers/fans. Another positive point of this is helping to promote a product that is not harmful to nature.

Please take a look $->$ http://bit.ly/mmoreambassadorpage

Looking forward to hearing from you soon and wishing you a great day :)

Best regards,

Ziga

5.0 Email correspondence with director of Mmore cases, on online brand which specializes in sustainable accessories.

The Ever After Club has and will continue to impact its community in a positive manner by encouraging informed and environmentally-conscious purchasing behaviour using an influential platform. Each post is carefully constructed using advanced photography, photo editing and insight into the world of social media through extensive research. The Ever After Club has helped to give a voice and a personality to the second-hand clothing industry which does not currently leverage social media to its full potential. As well as providing more of an online presence to the second-hand clothing market and a level of organization and connection between 
second-hand Toronto stores and potential consumers, The Ever After Club continually suggests ways in which individuals can get involved in sustainable practices. The mission remains clear as the project grows and expands from promoting just second-hand clothing to promoting sustainable purchasing and practices across all areas of the retail industry.

In the preliminary stages of this project, it was important to establish a target audience that was not too broad. This entrepreneurial practice is known as establishing the "beach head market" or "early adopters" (Wise n.d.). Starting with a small but loyal following that will eventually expand as the brand does is infinitely more beneficial than casting a wide net and trying to promote to a large, undefined audience. As The Ever After Club begins to take root and develop, the target demographic will expand from millennial women in Toronto with access to technology to millennial women in Canada and eventually beyond. As well as expanding from millennial women in Toronto to millennial women everywhere, this project will eventually begin to target young men as well. Young men have an equal responsibility to practice mindful consumption and make sustainable choices in their day-to-day consumer habits. The Ever After Club will begin displaying second-hand men's clothing as well as women's by December 2018 .

The Ever After Club page aims to integrate itself seamlessly into the lives of its users and followers, the way all successful digital media does, approaching issues of environmental sustainability in a manner that is relevant and engaging to its target demographic while simultaneously disrupting the intended purpose of Instagram by promoting conscious consumer behaviour as opposed to the mindless consumption that Instagram often facilitates. 


\section{Chapter 6.0: Research Methods and Results}

Secondary data was incredibly important to the development of this project and acted as evidence behind many major decisions. The Kijiji second-hand market index report for 2018 analyzes the second-hand economy in Canada and breaks down men and women's activity into 'disposals' and 'acquisitions.' The index confirmed that clothing made up the largest component of the Canadian second-hand industry though this is a result more of disposals than of acquisitions. This information helps to legitimize the fact that there is a need to reframe textile goods as non-transient. Furthermore, understanding through secondary research that the largest contributors to fast fashion are millennial women with access to technology made clear whom this project would target within the city of Toronto. 


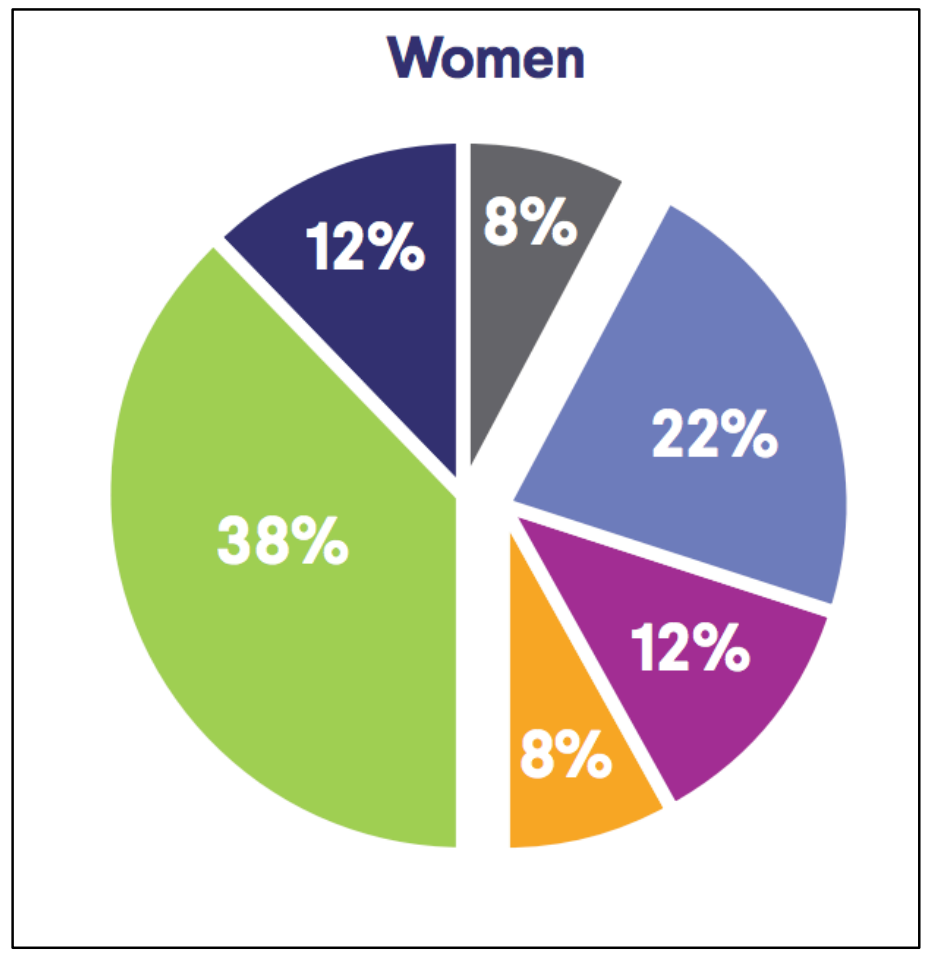

Figure 6.0 Canadian women's activity in the secondhand market (Durif, F. et Al. 2018).

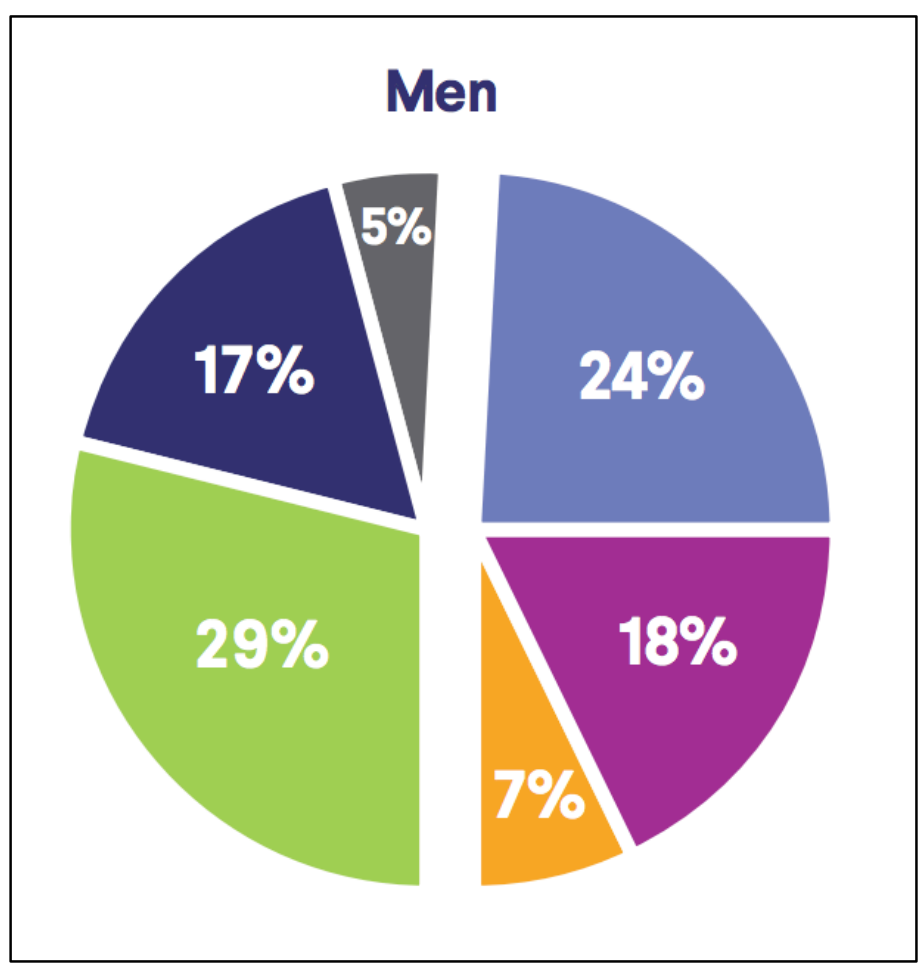

Figure 6.1 Canadian men's activity in the secondhand market (Durif, F. et Al. 2018).

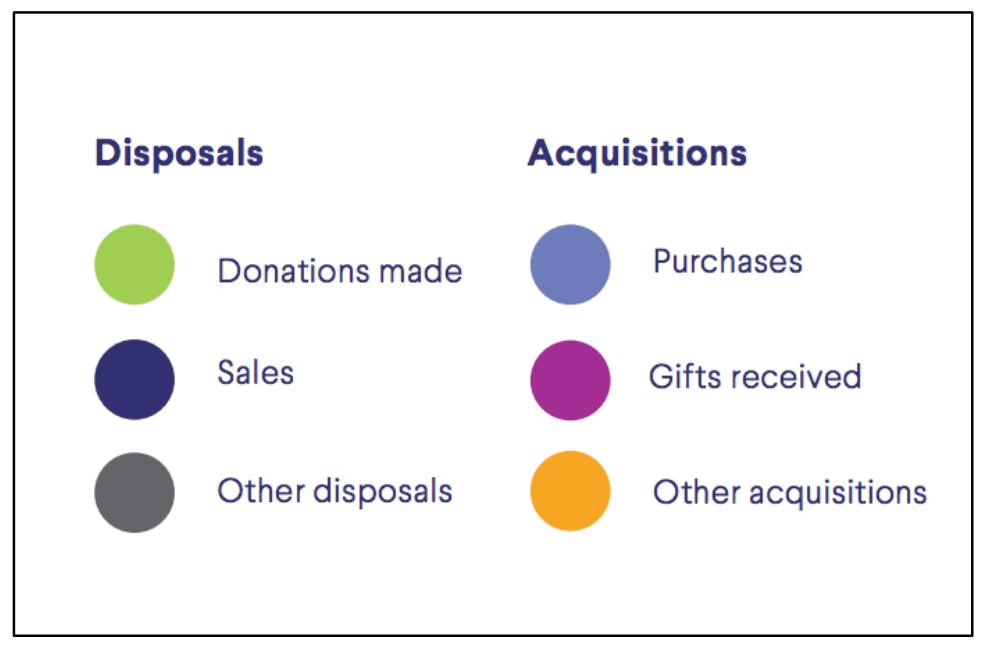


Once the evidence had been gathered as to who this social endeavour would target, it was imperative to collect primary data through specialized questionnaires that lent to expose what kind of media appealed to this demographic and through which platform messages of sustainability in fashion and mindful consumption would be best received.

Within the social media sphere, the most popular and widely recognized platforms for culture, lifestyle and fashion are Pinterest and Instagram. According to Pinterest's Business site, they gross 200 million users monthly on the world stage, $70 \%$ of whom are women (Pinterest 2018). Comparatively, $68 \%$ of Instagram users are female though Instagram has recently reached a billion monthly users worldwide. The survey created for this study aimed to determine between these two platforms which would more effectively engage the target audience. Prior to distribution, the questions and intentions of the survey were reviewed and approved by the Ryerson Research Ethics Board (See Appendix E). The anonymous survey was created using SurveyMonkey and was posted to Facebook stating the purpose of the study, confirming people's consent and outlining who was eligible to complete the survey. Of the 30 responses from the survey, $88 \%$ of the demographic in question preferred Instagram to Pinterest and that Instagram was the preferred platform for discovering fashion pages, clothing brands and style inspiration.

A second survey, also reviewed and approved by the Research Ethics Board, helped to shape the look and feel of The Ever After Club based on feedback from this project's target demographic. Figure 6.2, 6.3, 6.4 and 6.5 feature screen captures from Instagram. The screen captures feature various thrift-focused Instagram pages: Value Village, Salvation Army, and a 
Toronto based thrift store called, Courage My Love. The final screen capture, figure 6.5, is The Ever After Club page. To confirm that the layout, design and aesthetic of the Ever After Club appealed to its target demographic of female millennials, the four screen captures were used in an online survey directed toward millennial women. The names of each page were not featured in the survey to avoid bias. Of the 32 responses received on the survey, $100 \%$ of the anonymous participants agreed that of the four pages, they would be most inclined to follow The Ever After Club page for fashion inspiration and information about second-hand and thrift clothing.

This survey assisted to validate that layouts, aesthetics and design are hugely important in capturing the attention and interest of millennial women and that currently, thrift and secondhand clothing pages on Instagram are not effectively attracting a female millennial audience. The survey also helps to prove that consumer behaviour and attitudes can be influenced through basic principles of design. 


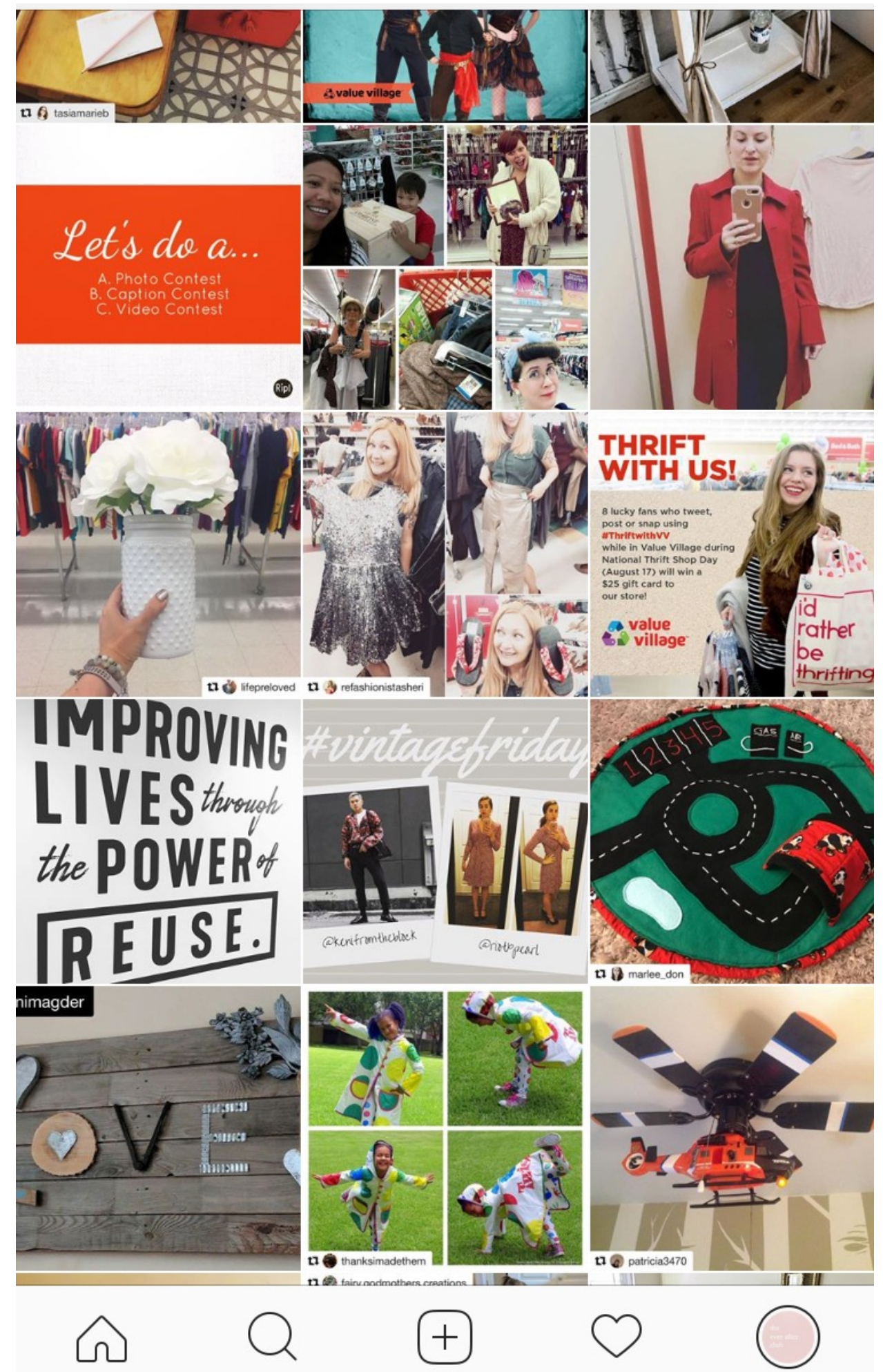

Figure 6.2 A screen capture from Value Village's Instagram Account 


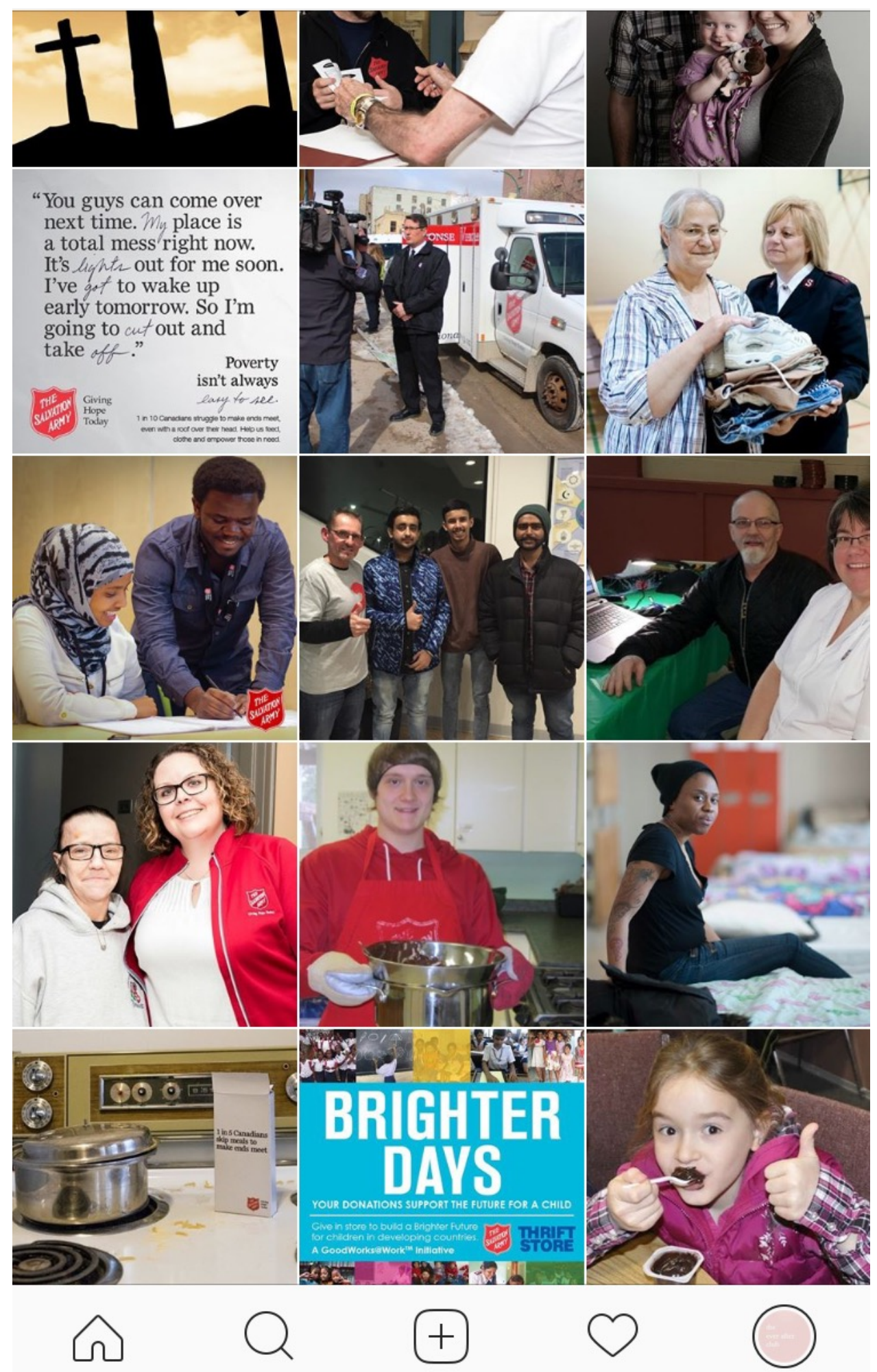

Figure 6.3 A screen capture from Salvation Army Canada's Instagram Page 


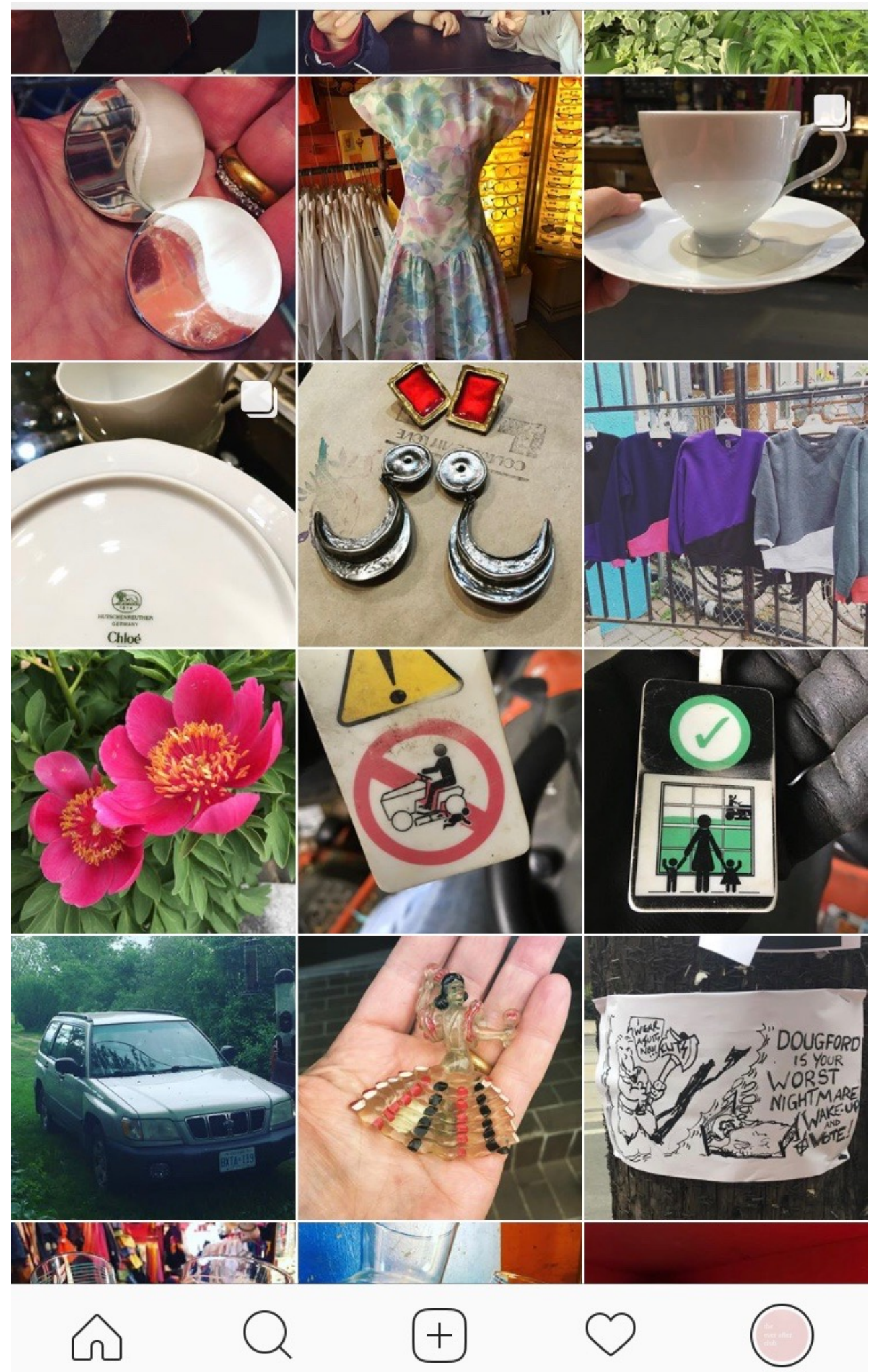

Figure 6.4 A screen Capture from Courage My Love's Instagram page 


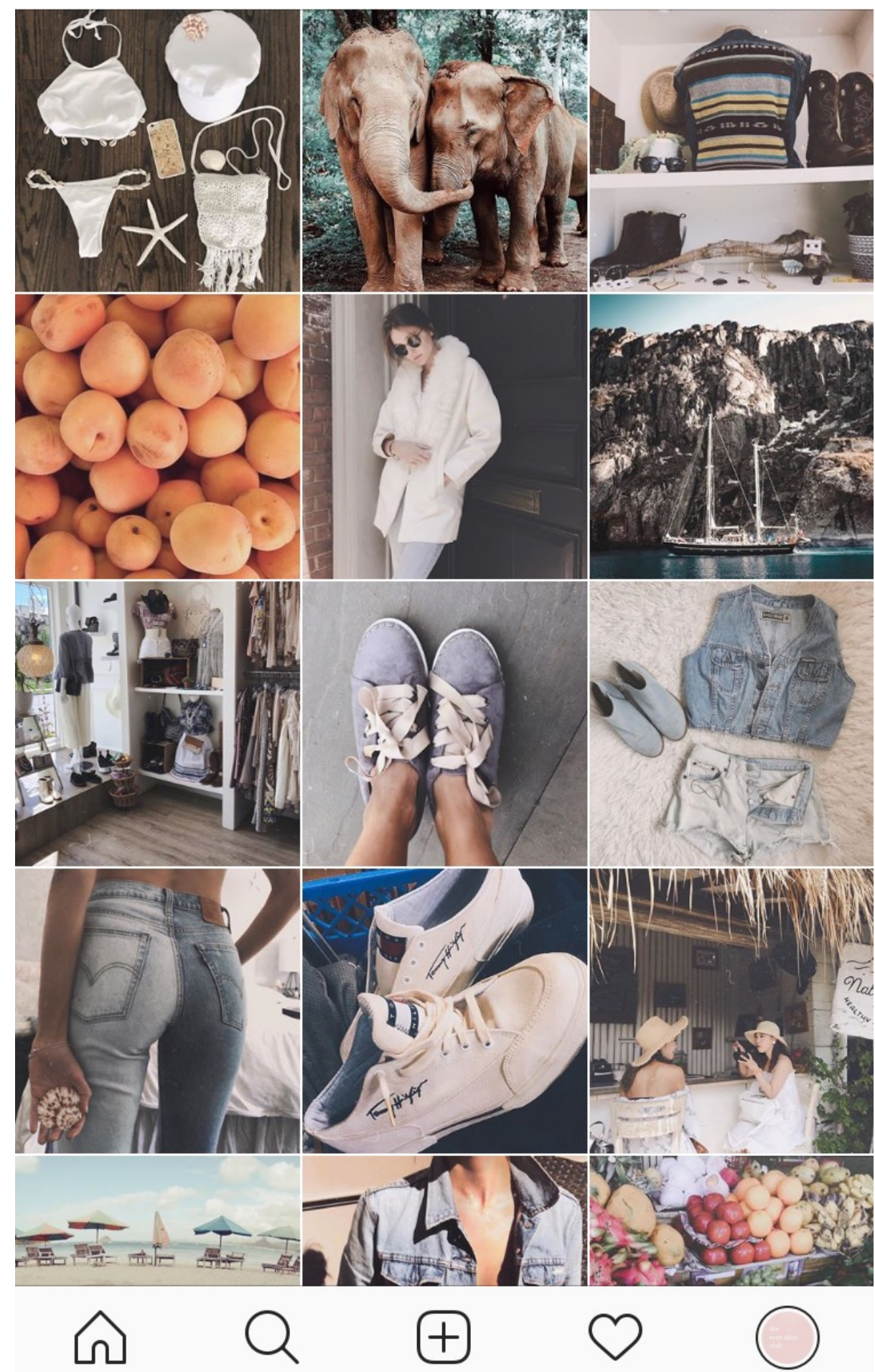

Figure 6.5 A screen Capture from The Ever After Club's Instagram page 
The same survey that was used to establish Instagram as the best platform for this project also confirmed a lack engagement between thrift stores and millennial women on social media. The survey asked participants if they followed any clothing brands or stores on Instagram and if they followed any thrift stores or second-hand clothing pages on Instagram. The results from the two questions are depicted below in figure 6.6 and 6.7. The Ever After Club aims to prove through these surveys not only the current lack of engagement but that with the proper marketing and branding techniques, a demand for thrift and second-hand clothing can be generated among this major demographic. 


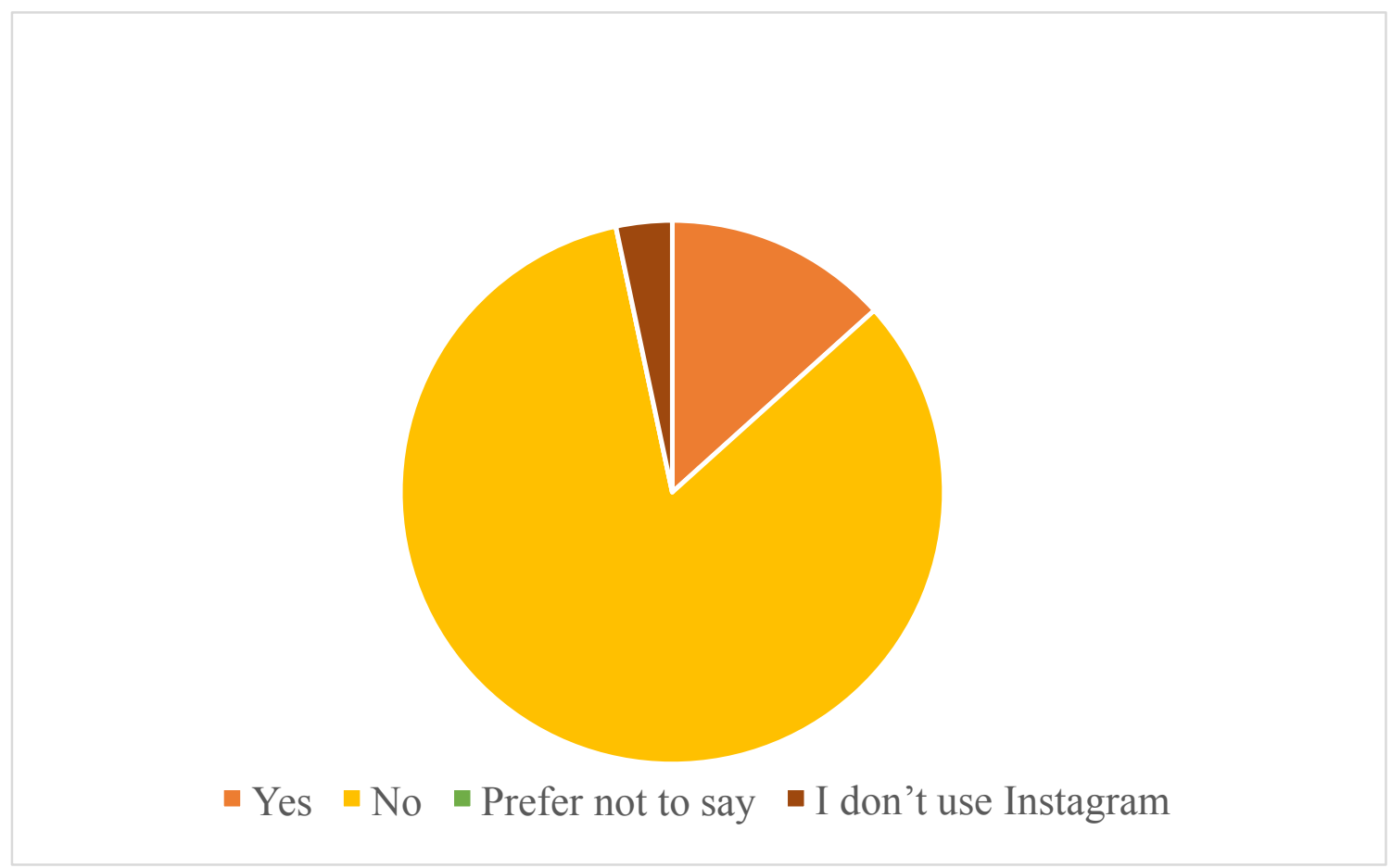

Figure 6.6 Responses to question, "Do you follow any thrift/second-hand clothing pages on Instagram?"

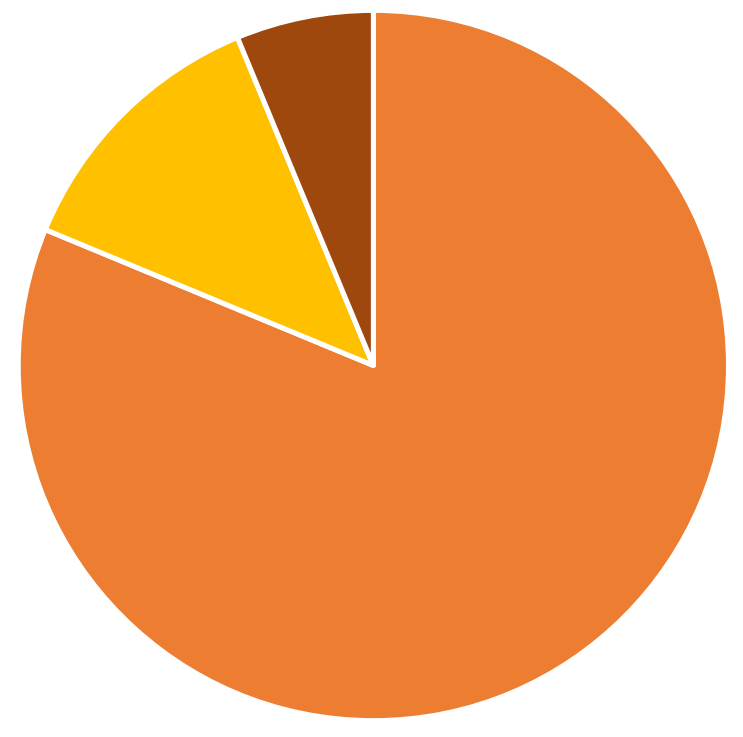

- Yes $\quad$ No $\quad$ Prefer not to say $\quad$ I don’t use Instagram

Figure 6.7 Responses to question, "Do you follow any clothing brands/companies on Instagram?" 


\subsection{User Engagement}

A major aspect of creating a successful and engaging Instagram page was using trial and error in addition to research into the industry to understand which tactics were effective and which were not. In order to attract the intended target audience, it was important to look at other fashion and clothing Instagram pages and go through their individual followers, following the users who matched the target audience criteria. The process was tedious but very beneficial for gaining traction from the target audience and was a major factor in gaining recognition and followers. In addition to manually selecting Instagram users to follow and target, The Ever After Club relied on the use of hashtags to increase reach. Hashtags allow for a given post to show up on more than one page so that they are viewed by a larger audience. At first it appeared that the most strategic way to gain traction through hashtags was to use as many hashtags as possible on a given caption. However, using fewer hashtags that were more relevant to the specific post and that related to the general purpose of the page such as "\#shopthrift" and "\#sustainablefashion" were much more effective. If too many hashtags were used and the hashtags were not relevant enough to the content, the post would actually receive fewer likes and less interaction than a different post which used fewer hashtags that were more relevant. Another important aspect of engaging users was actively liking and commenting on photos which encouraged people to want engage in return. 


\section{Conclusion}

In a society driven by consumerism, immediacy and efficiency, using social media to target millennial women and promote a shift in purchasing behaviour is the most logical and actionable solution. Highlighting the benefits of the second-hand clothing industry and promoting it through a popular platform helps to normalize the practice of buying and selling second-hand clothing and thrifted clothing among this demographic. Through the implementation of the Ever After Club page it was established that there is a market and an interest among millennial women to get involved in the second-hand clothing market if it was made to look and feel appealing. This project studied and leveraged popular marketing techniques used on Instagram to promote mass consumerism and subverted those techniques to create a public that engaged in mindful purchasing. Therefore, this project reimagined an existing tool in digital media for a purpose rooted in social good. The technique of repurposing pre-existing tools for new purposes reflects the basis of the project itself: reimaging the role and value of used clothing. Within the field of environmental sustainability in the media, this project was able to break new grounds by reframing environmental sustainability as an achievable goal and as something enjoyable and positive as opposed as a punishment or a threat.

Currently, the second-hand market in Toronto does not have a strong online presence and the stores themselves are often disorganized and overwhelming. This project uses the features of Instagram to break down the second-hand clothing market in Toronto and create an organized guide of Toronto thrift and consignment stores through videos and photos on the page. The project was developed through Instagram because it is a tool that is already integrated and familiar to the target audience and reflects the idea of reusing and repurposing existing resources. 
The title, The Ever After Club, emphasizes the idea of giving second-hand clothing a 'happily ever after' and as a way to describe a new way of orienting oneself towards material goods - an approach that brings on a sense of lightness, a clear conscience. 
Appendix A

The "Highlights" Feature on The Ever After Club Page

+2 theeverafterclub $\vee$, III D

\begin{tabular}{|c|c|c|}
\hline $\begin{array}{c}45 \\
\text { posts }\end{array}$ & $\begin{array}{c}325 \\
\text { followers }\end{array}$ & $\begin{array}{l}94 \\
\text { owing }\end{array}$ \\
\hline Promote & Edit Profile & 0 \\
\hline
\end{tabular}

Personal Blog

Toronto-based blog creating new styles and looks from local consignment \& thrift shops

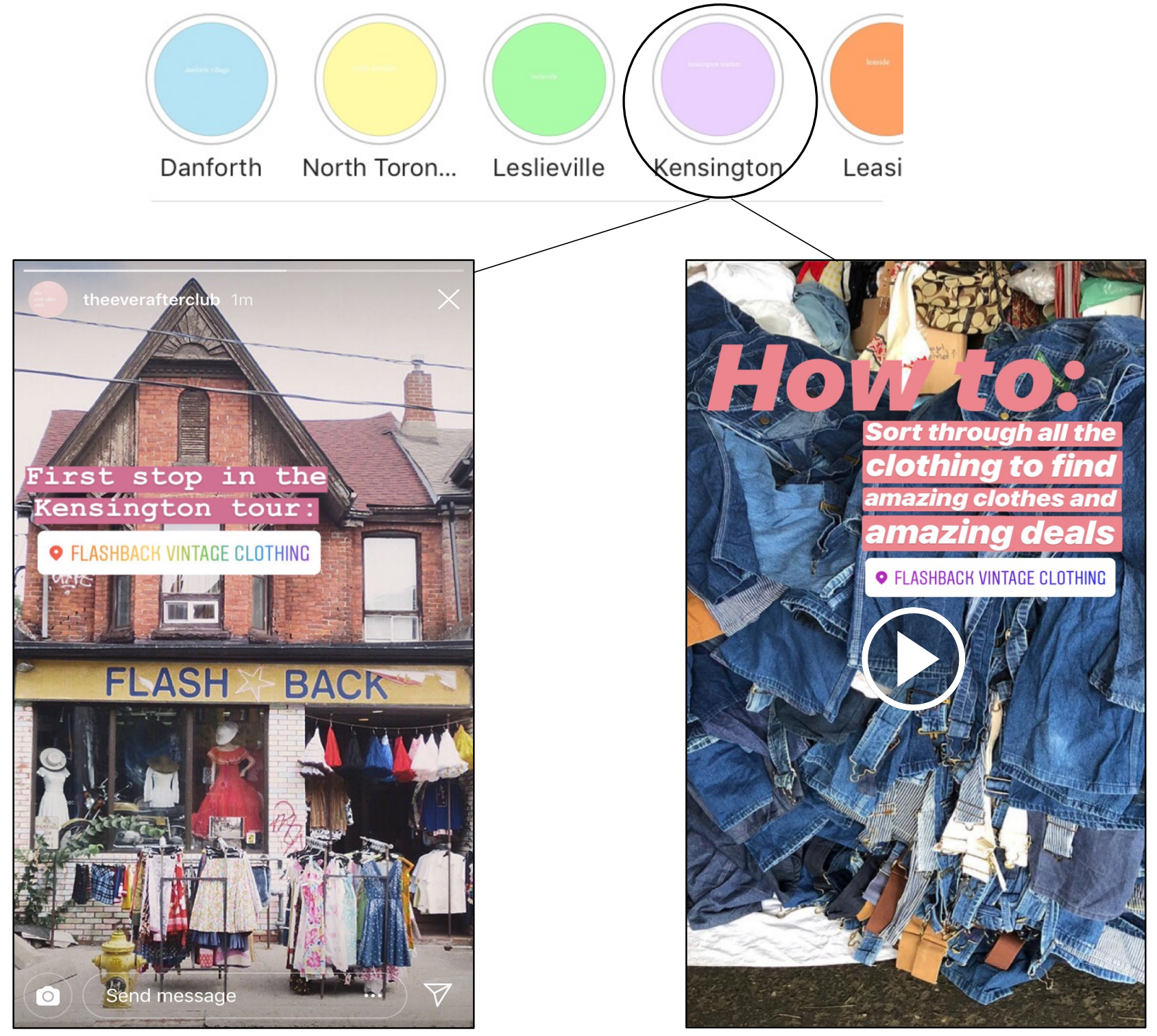




\section{Appendix B}

Popular Fashion Accounts and photographs on Instagram that influenced The Ever After Club's Aesthetic
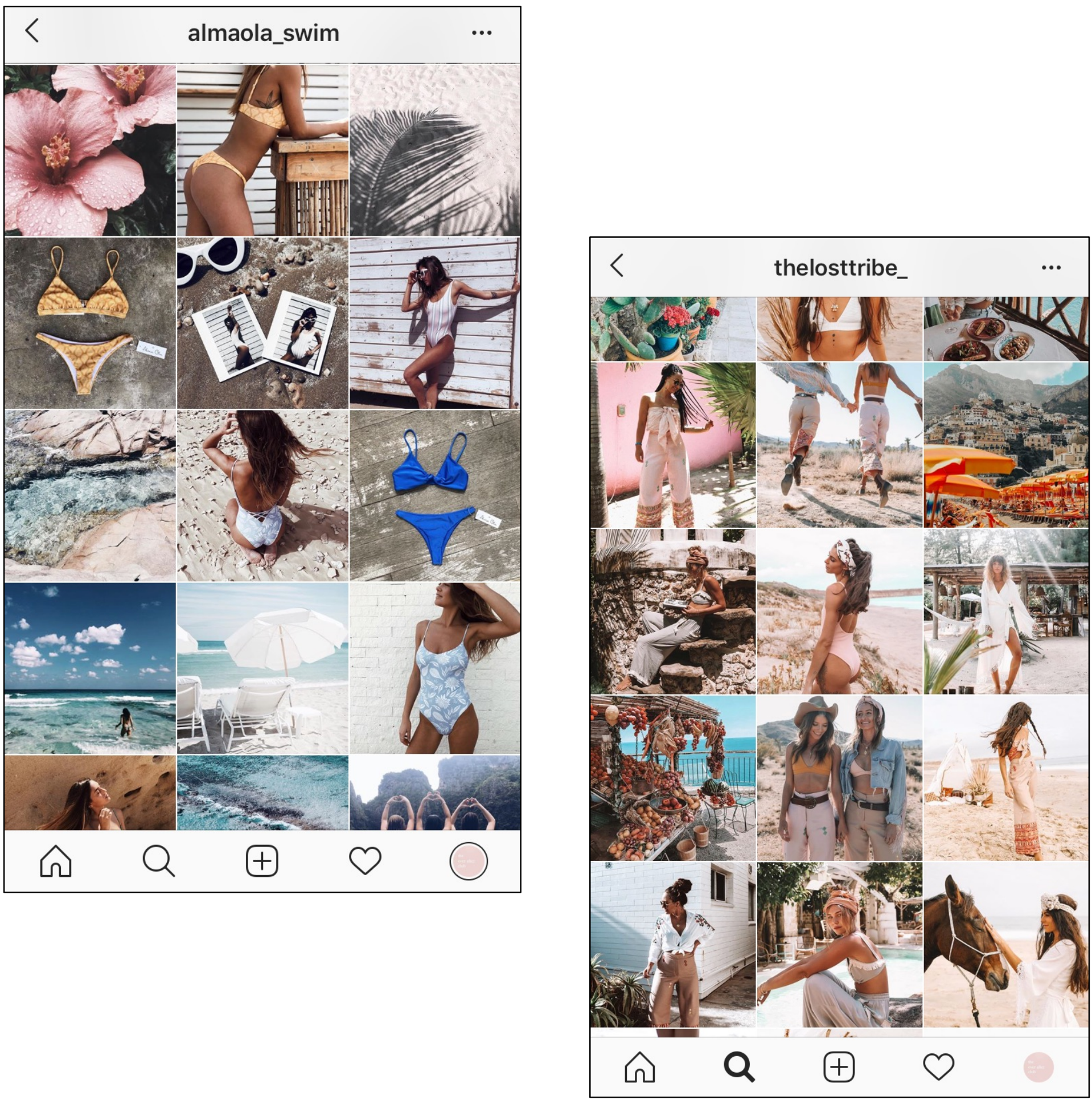

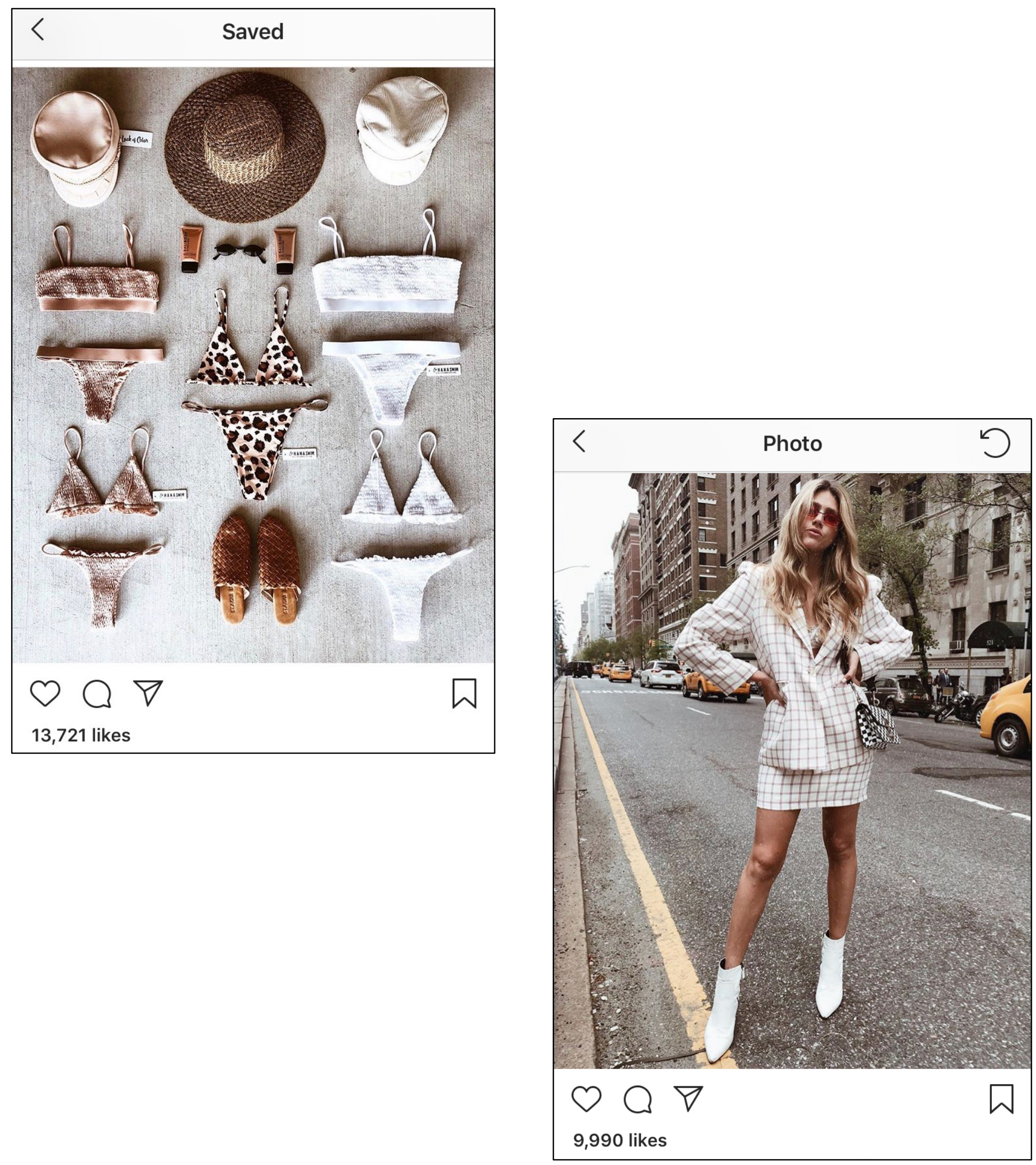
Appendix C

Instagram Inquiries from Interested Buyers

Hey! Love your page :) just wondering if you ever sell any of your items or if you just blog them? I am interested in buying the denim vest. Thanks!

ODouble tap to like

Write a message...

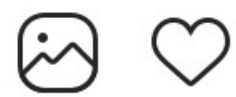

Hi! Wondering if any of the items on your page are for sale?

ODouble tap to like

(O) Write a message...

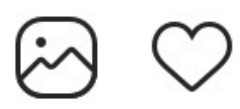

Very interested in buying.

Just sent you a DM

4h 1 like Reply

\section{Add a comment as theeverafterc...}




\section{Appendix D \\ Nuan's report and Business Application}

\section{ServiceOntario}

Please complete the following information.

Business/Operating/Trade Name (Required)

The Ever After Club

Clothing Resale

Session ID: 10870685

ServiceOntario Privacy Statement

Person Authorizing Registration - First Name

Person Authorizing Registration - Middle Name

Person Authorizing Registration - Last Name

Business/Operating/Trade Name

Business Activity (Required)

Is the address of your place of business in Ontario?

(Required)

POntario
ELSPETH

ANNA

POULSON

THE EVER AFTER CLUB

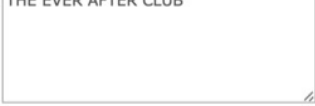

CLOTHING RESALE

Yes

No

Order Summary

Details

Payment to: ServiceOntario - Integrated Business Services Application (IBSA)

Total: $\$ 60.00$ (CAD) 


\section{Order a Nuans report - Nuans}

\section{Step 1 of 5: Propose a corporate name}

No exact matches for "The Ever After Club". There may still be similar names, however.

Propose a corporate name The Ever After Club

Cancel 


\section{References}

Audience demographics \& user stats. (2018). Retrieved from

https://business.pinterest.com/en/audience-demographics-user-stats.

Borgie, L. (2014). Trends in producer prices between e-commerce and brick-and-mortar retail trade establishments. Beyond the Numbers: Prices and Spending, vol. 3, no. 18 (U.S. Bureau of Labor Statistics, August 2014).

Braungart, M., \& Mcdonough, W. (2010). Cradle to Cradle. N.p.: Farrar, Straus and Giroux.

Braungart, M., \& Mcdonough, W. (2013). The Upcycle: Beyond Sustainability--Designing for Abundance. N.p.: Farrar, Straus and Giroux.

Case, A. (2015). Calm technology: Principles and Patterns for Non-Intrusive Design. O'Reilly Media.

CBC News. (2018). Clothes from Canada account for huge waste |CBC Marketplace [Video].

Cialdini, R. B. (2016). Influence science and practice. Brantford, Ontario: W. Ross MacDonald School Resource Services Library.

Claudio, L. (2007). Waste Couture: Environmental Impact of the Clothing Industry.

Environmental Health Perspectives, 115(9), A449-A454. http://dx.doi.org/10.1289/ehp.115-a449

D'Avella, M. (Director). (2015). Minimalism: A Documentary on the Important Things [Video file]. USA. Retrieved from

https://www.netflix.com/watch/80114460?trackId=13752289\&tctx=0,0,1871e420-c337-443f9930-5af5a7c6abb9-225669765,

Durif, F. et Al. (2018). The 4th Annual Kijiji Second-Hand Economy Index 2018 Report. Kijiji Canada Ltd.

Fletcher, K. (2008). Sustainable fashion and textiles. Earthscan.

Fletcher, K. (2012). Fashion and Sustainability: Design for Change.

Kittaneh, F. (2015, April 20). Use Content Marketing to Sell a Lifestyle, Not a Product.

Linden, Annie Radner, "An Analysis of the Fast Fashion Industry" (2016). Senior Projects Fall 2016. 30. http://digitalcommons.bard.edu/senproj f2016/30 
Miller, K. (2013). Hedonic customer responses to fast fashion and replicas. Journal of Fashion Marketing and Management: An International Journal, 17(2), 160-174.

Morley, N et Al. (2006, September). Recycling of Low Grade Clothing Waste (Rep. No. DEFR01 058). Retrieved June 18, 2018, from Oaken Hollins website.

Naranjo, D. "The Impact of Technology on Consumerism" (2015). CUNY Academic Works. https://academicworks.cuny.edu/gc_etds/1067

Okazaki, S. et. Al (2010). Global Consumer Culture Positioning: Testing Perceptions of Soft-Sell and Hard-Sell Advertising Appeals Between U.S. and Japanese Consumers. Journal of International Marketing, 18(2), 20-34. doi: 10.1509/jimk.18.2.20

Pipher, M. (2012). The green boat: Reviving ourselves in our capsized culture [Television series episode]. (2012, November 3). In TEDx. Retrieved July 18, 2018, from https://www.youtube.com/watch?v=iozxLbuPiX4

The Price of Fast Fashion. (2018). Nature Climate Change, 8.

S. (2018, June). Instagram: Active users 2018. Retrieved from https:/www.statista.com/statistics/253577/number-of-monthly-active-instagram-users/

Thorpe, J. (2017). Bustle Asked 1000 Millennial Women About Their Goals, Their Fears, And Their Hopes For The Future, \& This Is What We Found.

Warner, M. 2002. "Publics and Counterpublics.” Quarterly Journal of Speech, 88 (4).

Wise, S. (n.d.). Re: Identifying Your Early Adopters [Video blog lecture]. Retrieved from http://program.100steps2startup.com/courses/take/step-9-identifying-your-earlyadopters/lessons/1296798-phase-2-step-9-5-52 